Article

\title{
Catalysis of an Aldol Condensation Using a Coordination Cage
}

\author{
Cristina Mozaceanu, Christopher G. P. Taylor ${ }^{\circledR}$, Jerico R. Piper, Stephen P. Argent and \\ Michael D. Ward * \\ Department of Chemistry, University of Warwick, Coventry CV4 7AL, UK; \\ Cristina.Mozaceanu@warwick.ac.uk (C.M.); C.Taylor.10@warwick.ac.uk (C.G.P.T.); \\ Jerico.Piper@warwick.ac.uk (J.R.P.); stephen.argent@nottingham.ac.uk (S.P.A.) \\ * Correspondence: m.d.ward@warwick.ac.uk
}

Received: 7 January 2020; Accepted: 24 January 2020; Published: 25 January 2020

check for updates

\begin{abstract}
The aldol condensation of indane-1,3-dione (ID) to give 'bindone' in water is catalysed by an $\mathrm{M}_{8} \mathrm{~L}_{12}$ cubic coordination cage $\left(\mathrm{H}^{\mathrm{w}}\right)$. The absolute rate of reaction is slow under weakly acidic conditions ( $\mathrm{pH} 3-4)$, but in the absence of a catalyst it is undetectable. In water, the binding constant of ID in the cavity of $\mathbf{H}^{\mathbf{w}}$ is ca. $2.4( \pm 1.2) \times 10^{3} \mathrm{M}^{-1}$, giving a $\Delta \mathrm{G}$ for the binding of $-19.3( \pm 1.2) \mathrm{kJ} \mathrm{mol}^{-1}$. The crystal structure of the complex revealed the presence of two molecules of the guest ID stacked inside the cavity, giving a packing coefficient of $74 \%$ as well as another molecule hydrogen-bonded to the cage's exterior surface. We suggest that the catalysis occurs due to the stabilisation of the enolate anion of ID by the 16+ surface of the cage, which also attracts molecules of neutral ID to the surface because of its hydrophobicity. The cage, therefore, brings together neutral ID and its enolate anion via two different interactions to catalyse the reaction, which—as the control experiments show-occurs at the exterior surface of the cage and not inside the cage cavity.
\end{abstract}

Keywords: host-guest chemistry; coordination cage; catalysis; crystal structure; supramolecular chemistry

\section{Introduction}

The use of self-assembled molecular containers such as coordination cages as catalysts for reactions that occur in the central cavity has provided some remarkable examples of synthetic hosts providing enzyme-like levels of the rate acceleration of reactions. The range of reactions that has been shown to be catalysed is now extensive [1-10].

Many examples of cage-based catalysis rely on the steric properties of the cavity to provide the catalytic effect. Thus, the early examples of the acceleration of Diels-Alder reactions occurred on the basis that co-location of the two components in the same cavity provided a high local concentration of the two reacting partners [11-14]. Unimolecular pericyclic reactions can be accelerated because the folding of the guest allows it to bind in the cage cavity, resulting in a conformation that is close to the transition state [15-19]. Catalytic effects based on the electronic properties of the cage have also emerged, with photoinduced electron transfer between components of the cage walls and a bound guest, triggering useful reactions [20-23]; and an improved artificial 'Diels-Alderase' has been demonstrated, based on the electronic activation of the dienophile component by hydrogen-bonding interactions between the cage and guest, showing substantial rate enhancements without the need for the diene to be co-located in the cavity [24]. Possibilities for cage-based catalysis have been extended by the encapsulation of small-molecule catalysts, from mononuclear organometallic species to polyoxometallates, inside cage cavities [25-27]: in these cases, the cage itself is not the catalyst, but it modifies the behaviour of the bound catalyst that operates inside a constricted environment quite different from that in the bulk solution. 
We have recently demonstrated examples of catalysis using an octanuclear, approximately cubic, $\mathrm{M}_{8} \mathrm{~L}_{12}$ coordination cage host denoted $\mathbf{H}$ or $\mathbf{H}^{\mathbf{w}}$, depending on external substituents (Figure 1) [10,28-30], which in water binds a wide range of hydrophobic guests in the central cavity, driven principally by the hydrophobic effect [31-33]. We note that a diverse range of octanuclear cages with the capacity to bind guests in the cavity is known [34-37]. The basis of guest binding in our hosts $\mathbf{H} / \mathbf{H}^{\mathbf{w}}$ in solution is well understood to the extent that we have developed a reliable predictive model for quantifying the guest binding free energies [38,39]. In addition to binding guests in the central cavity, the high positive charge [+16, arising from eight $\mathrm{Co}(\mathrm{II})$ ions] results in the accumulation of anions around the cage surface, resulting in a high local concentration of anions surrounding the guest, which is the basis for the catalysis $[29,30]$. We also showed that the binding of anions to the cage surface depends on how readily the anion can be desolvated, with chloride ions displacing hydroxide, and in turn, phenolate anions displacing chloride ions [30], allowing the nature of the anionic reaction partner surrounding a guest to be controlled. Thus, the cage offers the possibility to co-locate (i) a substrate that binds via the hydrophobic effect, with (ii) a high concentration of anions that accumulate around it via ion-pairing, two orthogonal interactions that, in combination, could promote a wide range of catalysed reactions between organic substrates and anions in water. We note that this accumulation of counter-ions around charged cages that can participate in catalytic reactions has also been exploited by Raymond et al. in the opposite sense: they used highly anionic cages to stabilise protonated forms of cavity-bound substrates, even at high $\mathrm{pH}$ values [18,40-42].

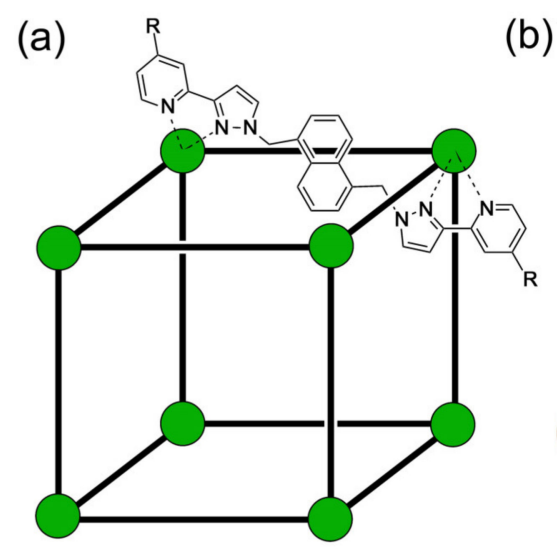

(b)

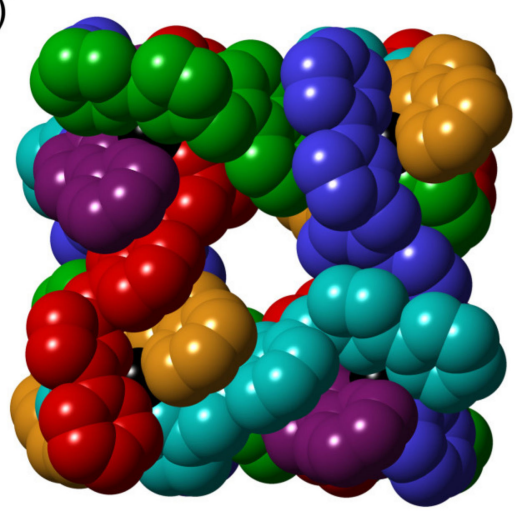

Figure 1. The octanuclear $\left[\mathrm{Co}_{8} \mathrm{~L}_{12}\right]\left(\mathrm{BF}_{4}\right)_{16}$ cages used in this work $\left(\mathrm{H}, \mathrm{R}=\mathrm{H},[28] ; \mathrm{H}^{\mathrm{w}}, \mathrm{R}=\mathrm{CH}_{2} \mathrm{OH},[31]\right)$. (a) A sketch showing the approximate arrangement of metal ions and the structural formula of the bridging ligands, which span every edge of the cubic array of $\mathrm{Co}(\mathrm{II})$ ions; (b) view of the cationic cage cavity with each ligand coloured separately (from [28]).

We report here that our cage system can catalyse an aldol reaction: the conversion of indane-1,3-dione to bindone (Scheme 1) [43-46]. This was discovered by accident when we were evaluating the binding constants of a range of possible guests using spectroscopic titrations in solution; the addition of indane-1,3-dione (abbreviated hereafter as ID) to an aqueous solution of $\mathbf{H}^{\mathbf{w}}$ resulted in the gradual appearance of a purple colour, which interfered with the titration experiment, but signalled the formation of the condensation product bindone. This did not occur in the absence of the cage under the same conditions. The facile aldol condensation of ID to give not just bindone, but also higher oligomers by multiple aldol-type reactions, has been known for over a century $[45,46]$ and was recently re-studied in detail $[43,44]$. As ID has a pKa of close to 7 , the reaction can occur under very mild conditions and can even be catalysed by the surface of laboratory glassware, meaning that spectroscopic studies need to be prepared and performed in either plastic or quartz vessels. 


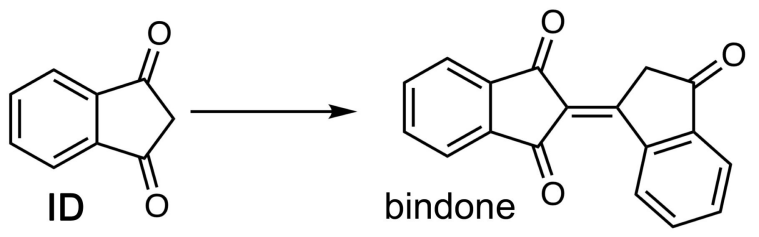

Scheme 1. Aldol condensation of indane-1,3-dione (ID) to bindone.

\section{Materials and Methods}

The Co(II)-based cage $\mathbf{H}^{\mathbf{w}}$ was prepared as its fluoroborate salt through a previously-published method [28]. Indane-1,3-dione was purchased from Sigma-Aldrich; it reacts slowly with atmospheric moisture, so was dried under high vacuum, and stored in a desiccator. The instrumentation used for routine spectroscopic measurements was as follows: ${ }^{1} \mathrm{H}-\mathrm{NMR}$ spectroscopy, a Bruker Avance $300 \mathrm{MHz}$ instrument; UV/Vis absorption spectra, an IMPLEN NanoPhotometer C40 cuvette reader, or BMG CLARIOstar plate-reader. Solution $\mathrm{pH}$ measurements were performed with a Hamilton Spintrode $\mathrm{pH}$ combination electrode calibrated with standards at $\mathrm{pH} 4.01$ and 7.00.

Measurement of the binding constant of ID in $\mathbf{H}^{\mathbf{w}}$ was performed as follows. A series of $13 \mathrm{NMR}$ tubes was prepared containing $0.6 \mathrm{~mL}$ of a $\mathrm{D}_{2} \mathrm{O}$ solution containing $0.2 \mathrm{mM} \mathrm{H}^{\mathrm{w}}$ at $\mathrm{pD}=3.8$, with the ID concentration varying from 0 to $1 \mathrm{mM}$ (i.e., 0 to 5 equivalents) across the series. Spectra were recorded at $298 \mathrm{~K}$ and signals where free and bound $\mathbf{H}^{\mathbf{w}}$ could be seen separately were deconvoluted and integrated to allow the calculation of $K$ (see main text).

Catalysis experiments were performed at $298 \mathrm{~K}$ using aqueous solutions containing $\mathbf{H}^{\mathbf{w}}(0.09 \mathrm{mM})$ and ID $(0.9 \mathrm{mM})$ at $\mathrm{pH} 3.4$ in a $1 \mathrm{~cm}$ path-length quartz cuvette. Progress was monitored on a UV/Vis spectrophotometer by growth in the absorbance of the product bindone at $550 \mathrm{~nm}$ (see main text).

The X-ray crystallographic data for the $\mathbf{H}^{\mathbf{w}} / \mathbf{I D}$ complex were collected in Experiment Hutch 1 of beamline I-19 at the UK Diamond Light Source synchrotron facility [47]. Full details of the instrumentation, methods used for data collection, and for the solution and refinement of the structure, are as recently published [48]. Crystallographic, data collection, and refinement parameters are collected in Table 1. CCDC deposition number: 1979819.

Table 1. Summary of crystallographic, data collection, and refinement parameters for $\mathbf{H \bullet}\left(\right.$ ID) ${ }_{3}$

\begin{tabular}{cc}
\hline Empirical formula & $\mathrm{C}_{398.15} \mathrm{H}_{435.65} \mathrm{~B}_{16} \mathrm{Co}_{8} \mathrm{~F}_{64} \mathrm{~N}_{74.85} \mathrm{O}_{39.35}$ \\
Formula weight & 8759.54 \\
$T / \mathrm{K}$ & $100(1)$ \\
Crystal system & Monoclinic \\
Space group & $C 2 / \mathrm{c}$ \\
Crystal size $/ \mathrm{mm}^{3}$ & $0.04 \times 0.04 \times 0.04$ \\
$a / \AA$ & $32.77108(17)$ \\
$b / \AA$ & $30.00687(16)$ \\
$c / \AA$ & $40.3365(2)$ \\
$\beta /$ degrees & $96.1279(5)$ \\
$V / \AA^{3}$ & $39,438.6(3)$ \\
$Z$ & 4 \\
$\rho_{\text {calc }} / \mathrm{g}$ cm & \\
$\mu / m^{-1}$ & 1.475 \\
Radiation & 0.405 \\
Reflections collected & 337,794 \\
Data/restraints/parameters & $62,798 / 5962 / 2330$ \\
Final $R$ indexes $[I \geq 2 \sigma(I)]$ & $R_{1}=0.0651, \mathrm{w} R_{2}=0.2094$ \\
Final $R$ indexes (all data) & $R_{1}=0.1117, \mathrm{w} R_{2}=0.2292$ \\
\hline
\end{tabular}




\section{Results}

To probe the cage-based catalysis of this reaction, we first examined the $\mathrm{pH}$ profile of the uncatalysed 'background' reaction, looking for conditions where this was as slow as possible to allow the effects of any catalysis to be most apparent. Monitoring the formation of bindone by UV/Vis spectroscopy (it has a strong absorption maximum at $510 \mathrm{~nm}$ in water) [44] at a range of different $\mathrm{pH}$ values showed that the reaction proceeds quickest in the $\mathrm{pH}$ range 6-7 where, based on the $\mathrm{pKa}$ of the starting material, there will be substantial amounts of both nucleophilic enolate anions and electrophilic neutral ID present; the reaction becomes slower at greater extremes of high or low $\mathrm{pH}$. To facilitate the analysis of the reaction by UV/Vis spectroscopy, we therefore performed our subsequent

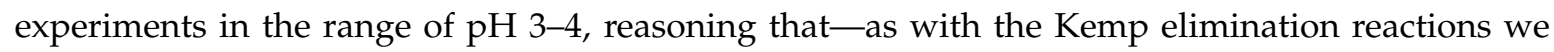
examined earlier $[29,30]$ - the high positive charge of the cage should stabilise the anionic enolate form of ID, even under relatively acidic conditions. Furthermore, at this $\mathrm{pH}$, the intense yellow colour of the enolate anion, which would make the observation of the emerging colour of bindone more challenging, was not present.

We measured the binding constant of ID in the cage cavity with a ${ }^{1} \mathrm{H} N \mathrm{NR}$ titration, adding several equivalents of ID in small aliquots to a $\mathrm{D}_{2} \mathrm{O}$ solution of $\mathbf{H}^{\mathbf{w}}$ at $\mathrm{pD} 3.8$ (when the uncatalysed aldol reaction is extremely slow). The evolution of the ${ }^{1} \mathrm{H}$ NMR spectra is shown in Figure 2 . It is clear that ID binds in the cage cavity in slow exchange with free guest in solution, as separate signals for free cage $\mathbf{H}^{\mathbf{w}}$, and the complex $\mathbf{H}^{\mathbf{w}} \bullet$ ID could be observed with the former progressively reducing in intensity and the latter increasing during the titration. The occurrence of a single signal for each host proton in the complex $\mathbf{H}^{\mathbf{w}} \bullet$ ID implies rapid motion of the ID guest in the cavity, such that the symmetry of the cage is preserved on the NMR timescale when the guest binds [49].

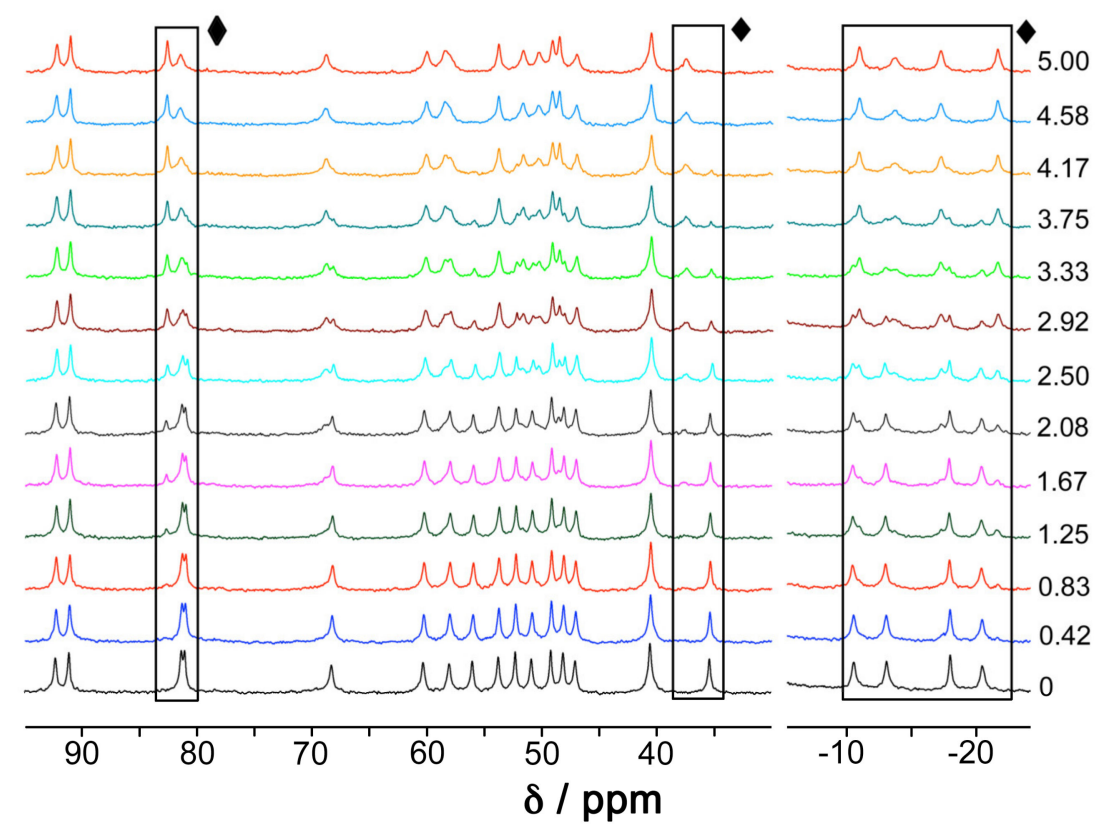

Figure 2. Evolution of paramagnetic ${ }^{1} \mathrm{H}$ NMR spectra during additions of ID ( $0-5$ equivalents, indicated for each spectrum on the right) to a solution of $\mathbf{H}^{\mathbf{w}}$ in $\mathrm{D}_{2} \mathrm{O}(298 \mathrm{~K})$. Signals associated with empty $\mathbf{H}^{\mathbf{w}}$ (bottom spectrum) are replaced by new signals for the $\mathbf{H}^{\mathbf{w}} \bullet$ ID complex as the titration proceeds. Regions where this is particularly clear, and separate signals for the free and bound cage can be deconvoluted and integrated, are shown by the black diamonds.

Estimates of the binding constant $K$ could be obtained by deconvoluting and integrating the separate (but closely spaced) $\mathbf{H}^{\mathbf{w}}$ and $\mathbf{H}^{\mathbf{w}} \bullet$ ID signals at several different points across the ${ }^{1} \mathrm{H}$ NMR spectrum for known concentrations of cage and added guest. In this case, the close overlap of signals for the free and bound cage, coupled with uncertainties associated with deconvoluting and integrating 
broad signals from a paramagnetic compound, resulted in a high uncertainty: the average value of $K$ obtained from several such measurements was $2.4( \pm 1.2) \times 10^{3} \mathrm{M}^{-1}$, where the e.s.d. quoted is double the standard deviation obtained from averaging multiple measurements. We note that our algorithm for estimating binding constants using molecular docking software with a customised scoring function suggested a binding constant of $1200 \mathrm{M}^{-1}[38,39]$, which is in good agreement with our estimate, and many structurally similar guests have binding constants in the $10^{3}-10^{4} \mathrm{M}^{-1}$ range $[31,38]$.

A crystal structure of the cage/guest $\mathrm{H} / \mathrm{ID}$ complex could be obtained using the crystalline sponge method that we have used in previous work by preparing crystals of the free host cage $\mathbf{H}$ by a solvothermal synthesis, followed by slow cooling [28], and immersing them in a concentrated solution of ID in MeOH for several hours, which resulted in guest uptake without loss of crystallinity [48]. Details of the structure are shown in Figures 3-5.
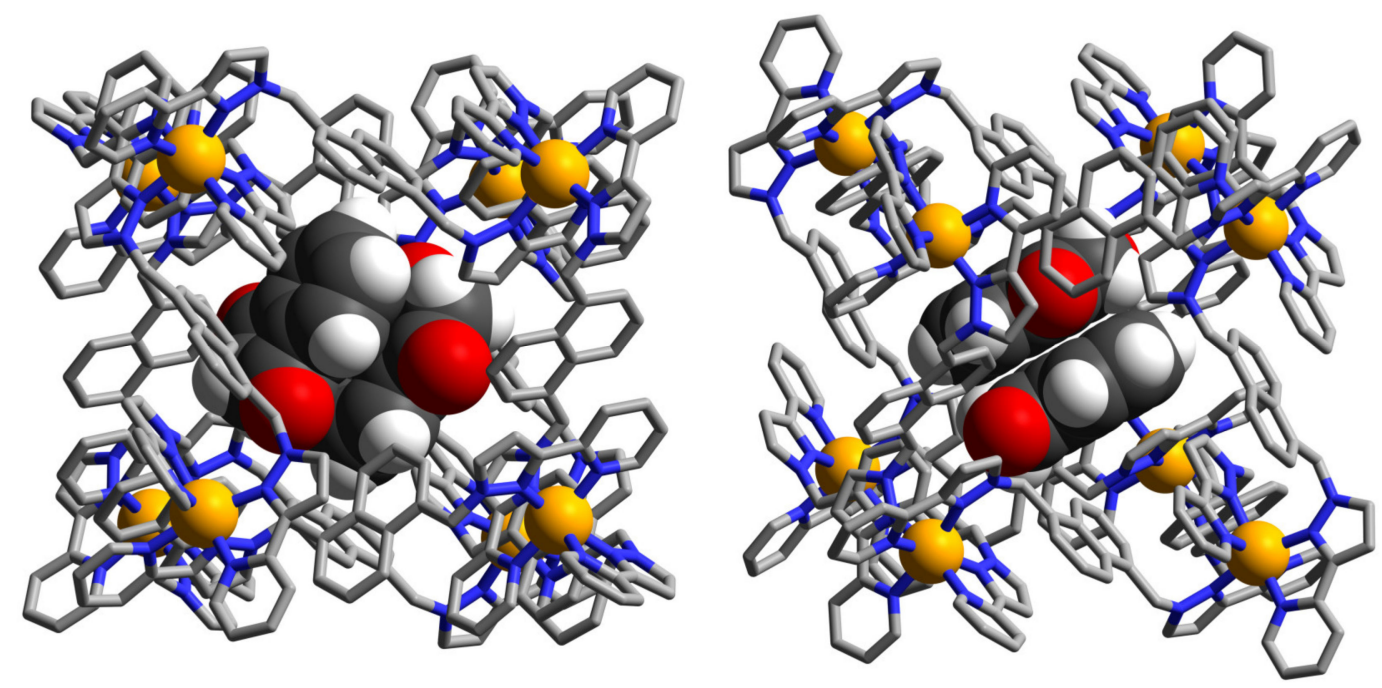

Figure 3. Two views of the crystal structure of the complex of host $\mathbf{H}$ with ID, showing the presence of a stacked pair of ID guests (which are shown in space-filling mode) in the cavity (host cage shown in wireframe) lying astride an inversion centre ( $\mathrm{N}$ atoms, blue; $\mathrm{O}$ atoms, red; $\mathrm{Co}$ atoms, orange; $\mathrm{C}$ atoms, grey).

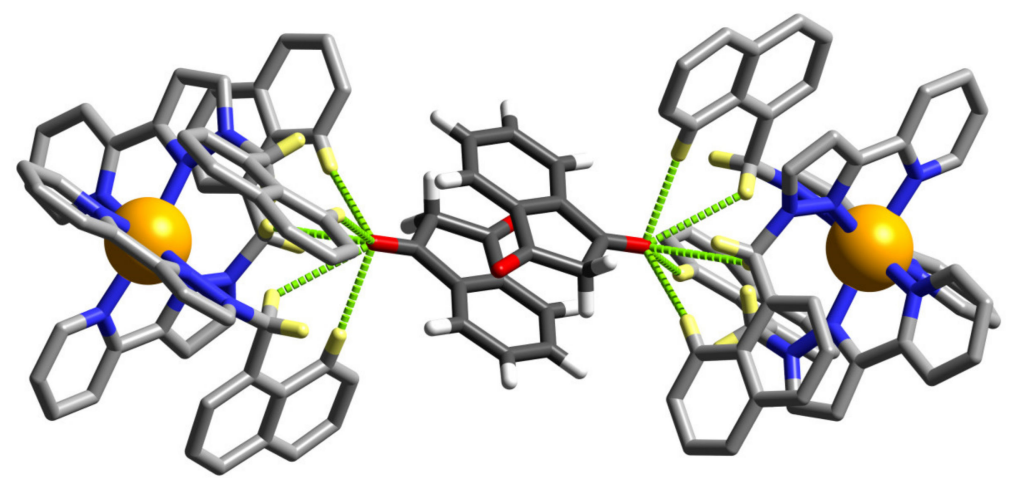

Figure 4. Partial view of the structure of the H/ID complex showing how each ID guest molecule forms a network of $\mathrm{CH} \cdots \mathrm{O}$ contacts (shown by green dotted lines) with a convergent set of $\mathrm{CH}$ groups associated with the cage interior surface around the two fac tris-chelate metal complex vertices of $\mathbf{H}$.

Rather than the expected one molecule of guest, which we have often observed in previous work, we found a pair of guests stacked across an inversion centre in the cage cavity (Figure 3). This is not a 50:50 disorder as each guest molecule (the two are crystallographically equivalent) refines with unit site occupancy, and the distance between them is typical of $\pi$-stacking (3.48 $\AA$ ). The combined volume of two ID guests (74\%) significantly exceeded the value of $55 \pm 9 \%$ of the host cavity volume $\left(409 \AA^{3}\right.$ ), which Rebek showed a while ago afforded optimal guest binding in 
solution [50,51]. However, a crystalline sponge experiment was performed under highly forcing and non-equilibrium conditions using a large excess of the guest; we [48] and others [52-54] have observed packing coefficients for guests inside supramolecular host cavities of $>80 \%$ when favourable interactions such as $\pi$-stacking between multiple guests and favourable interactions between guests and the cage interior surface result in a particularly compact guest array. In dilute solution-the conditions under which guest binding is normally evaluated-we can imagine that for this reason, the second binding constant $K_{2}$ would be substantially smaller than the first binding constant $K_{1}$, in which case, the single-guest binding would dominate the solution speciation behaviour [48].

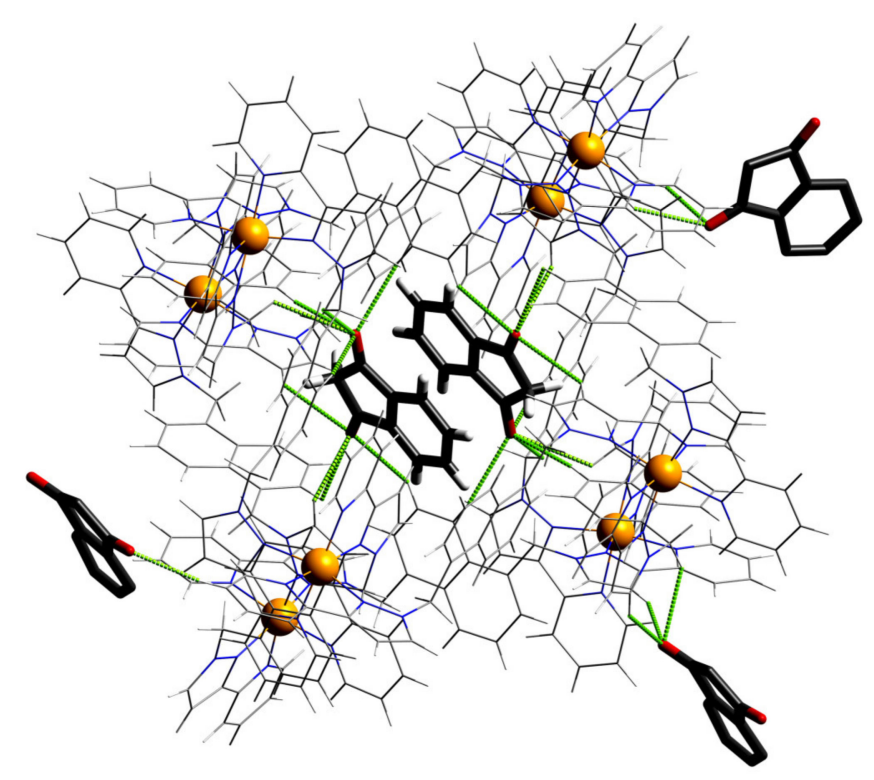

Figure 5. A view of the crystal structure of the complex of host $\mathbf{H}$ with ID, emphasising how the host cage brings together molecules at binding sites inside the cage cavity (cf. Figure 3 ) and around the exterior cage surface. It is not possible to tell whether the external guests are neutral ID or are the enolate anions stabilised by the high positive charge of the cage surface.

The (crystallographically equivalent) guests interact with the cage interior surface through multiple $\mathrm{CH} \cdots \mathrm{O}$ hydrogen bonds between the ketone $\mathrm{O}$ atoms, which are weak hydrogen-bond acceptors, and inwardly-directed $\mathrm{C}-\mathrm{H}$ bonds from the ligand set, whose ability to act as weak $\mathrm{H}$-bond donors is improved by the high positive charge of the assembly (Figure 4) [49,55]. One of the O atoms $[\mathrm{O}(14 \mathrm{G})]$ lies in an $\mathrm{H}$-bond donor pocket close to a fac tris-chelate metal ion, which contains several convergent $\mathrm{CH}$ groups (from methylene $\mathrm{CH}_{2}$ and naphthyl $\mathrm{CH}$ protons) whose combined $\mathrm{H}$-bond donor effect is comparable to a phenol group in terms of its overall hydrogen-bond donor strength $[49,55]$. The penetration of one of the $\mathrm{C}=\mathrm{O}$ groups of the ID guest into this pocket results in non-bonded $\mathrm{H} \cdots \mathrm{O}$ distances associated with these $\mathrm{CH} \cdots \mathrm{O}$ interactions in the range of 2.5-3 $\AA$. The other carbonyl $\mathrm{O}$ atom $[\mathrm{O}(15 \mathrm{G})]$ likewise forms $\mathrm{CH} \cdots \mathrm{O}$ interactions with inwardly-directed naphthyl and pyrazolyl $\mathrm{CH}$ protons from the cage surface, with $\mathrm{O} \cdots \mathrm{H}$ distances of $2.8-2.9 \AA$.

There is an additional molecule of ID in each asymmetric unit (which contains half of a complete cage unit). This was refined with a site occupancy of 0.42 ; it lies in the space between cage molecules, and interacts with the cage exterior surface (Figure 5) through a similar set of $\mathrm{CH}$... O hydrogen-bonds, as we saw for the interior guests, with $\mathrm{O} \cdots \mathrm{H}$ distances in the range 2.5-2.7 $\AA$ [thus the overall formulation, ignoring solvent molecules, is $\left.\mathbf{H \bullet}(\text { ID })_{2.84}\right]$. We have assumed, for the purposes of the crystallographic refinement, that this is a neutral ID molecule incorporating a $\mathrm{CH}_{2}$ fragment between the two ketones. However, the possibility exists that this could be the enolate anion of ID, stabilised by the highly cationic cage surface. For a structure of this type (a large supramolecular assembly with weak scattering due to solvent/anion disorder), there is no way to ascertain this crystallographically. 
Marginal differences in the $\mathrm{C}-\mathrm{C}$ and $\mathrm{C}-\mathrm{O}$ distances between the neutral and enolate forms of ID are not meaningful, given the extensive use of geometric restraints in the refinement (see CIF for details, Supplementary Materials), and charge balance considerations are not helpful either due to the solvent/anion disorder that required the use of SQUEEZE [56] to eliminate diffuse electron density from the refinement. We note, however, that the $\mathrm{CH} \cdots \mathrm{O}$ H-bonding interactions between the carbonyl oxygen atoms of the external ID molecule and the $\mathrm{CH}$ groups of the cage surface are shorter, on average, than those of the cavity-bound guest, consistent with the 'external' guest being in its anionic form. Whether the 'external' ID molecules in the crystal structure are in the neutral form or are actually the enolate anions, this structure provides a nice illustration of how the cage host can simultaneously co-locate a hydrophobic guest (in the cavity) and additional reaction partners around the exterior surface [30].

Catalysis experiments were performed with an aqueous solution of $\mathbf{H}^{\mathbf{w}}(0.09 \mathrm{mM})$ and up to 10 equivalents of ID at $\mathrm{pH} 3.4$ (Figure 6). Under these conditions, in the absence of the cage, no measurable conversion of ID to bindone was seen over prolonged periods (days), presumably due to the absence of any significant amount of the enolate anion of ID. Metal fluoroborate salts on their own, likewise had no catalytic effect. However, in the presence of cage $\mathbf{H}^{\mathbf{w}}$, steady growth in the absorbance associated with bindone was seen. This has a maximum at $510 \mathrm{~nm}$, but it was monitored at $550 \mathrm{~nm}$ to avoid any possible competition from absorbance associated with the enolate anions, which is significant at $510 \mathrm{~nm}$. The virtually straight-line growth of bindone over this period of time means that the reaction progress cannot meaningfully be fitted to a specific kinetic model; leaving the reaction for longer to let more bindone form results in solutions becoming cloudy as the product has poor water solubility. We can say, however, that after $12 \mathrm{~h}$, around $3 \%$ of the ID was converted to bindone, increasing to $10 \%$ after $36 \mathrm{~h}$, corresponding to approximately one turnover per catalyst molecule over $36 \mathrm{~h}$. Although the absolute rate of the formation of bindone catalysed by the cage is therefore extremely low, compared to the undetectable formation of bindone in the absence of catalyst at this $\mathrm{pH}$, the catalysis of the reaction under these conditions is clear.

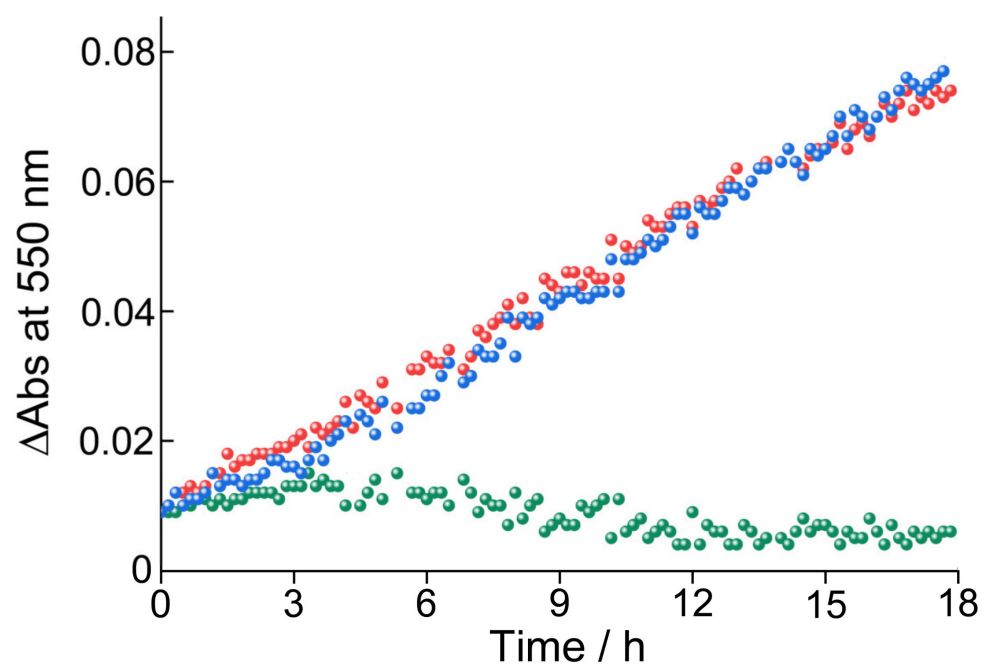

Figure 6. Cage-catalysed conversion of ID to bindone ( $0.9 \mathrm{mM}$ ID at start; $298 \mathrm{~K}$, pH 3.4), performed in a UV/Vis cuvette and monitored by measuring the increase in optical density at $550 \mathrm{~nm}$ arising from product formation. Green circles represent the background reaction (no significant reaction in the absence of cage $\mathbf{H}^{\mathbf{w}}$ ). Red circles represent the progress of the reaction in the presence of $0.09 \mathrm{mM}$ $\mathbf{H}^{\mathbf{w}}$ (i.e., the catalysed reaction). Blue circles represent catalysis under the same conditions as the red circles, but with $1.8 \mathrm{mM}$ cycloundecanone added to block the cage cavity, showing that blocking the host cavity does not inhibit the catalysis, which must therefore occur at the external surface of the cage (see main text). 
Control experiments suggested that the reaction does not actually occur inside the cage cavity, but at the external surface, which is a possibility that has very recently emerged from related studies on catalysis with this cage system [57]. In the confined space of the cavity, any successful reaction would require an ideal configuration of the cavity-bound and surface-bound reacting partners, and when this happens, it can lead to very large rate enhancements [10,29]. However, hydrophobic substrates that do not bind in the cavity, or that cannot react for geometric reasons whilst inside the cavity, can also interact with the cage exterior surface, which is just as hydrophobic as the interior surface and has a greater area: these substrates can thereby be brought into the region around the cationic surface where anions have accumulated because of ion-pairing effects [57]. The key control experiment here is to perform the reaction in the presence of an excess of cycloundecanone. This binds strongly in the cage cavity $\left(>10^{6} \mathrm{M}^{-1}\right)$ [32] and therefore prevents the substrate ID from binding, however, it has no effect on the rate at which bindone is formed. This clearly indicates that cavity-based binding of ID is not necessary for the catalysis to occur, therefore it follows that the catalysed reaction occurs at the external surface of the cage where enolate anions of ID accumulate [57].

\section{Discussion}

Clearly the aldol condensation of two molecules of ID to bindone is catalysed by the presence of the cage. A plausible mechanism is that the hydrophobic, but cationic surface of the cage stabilises the enolate anion of ID, effectively reducing its $\mathrm{p} K_{\mathrm{a}}$, so that when close to the cage, it can be deprotonated even at $\mathrm{pH} 3.4$ when the expected $\mathrm{p} K_{\mathrm{a}}$ is 7 . We emphasise that 'soft' anions such as phenolates have already been shown to have a higher affinity for the cage surface than more highly solvated anions such as hydroxide or chloride [9]. It is also significant that Raymond and co-workers observed that the basicity of an amine could be increased by $>4 \mathrm{pK}$ a units when the amine is bound inside a cage host with a charge of -12 [42]: the charge of +16 on $\mathbf{H}^{\mathbf{w}}$ implies that a comparable increase in the acidity of ID (i.e., stabilisation of the enolate anion) is plausible if the anion is interacting with the cage surface. As the cage can also bind neutral ID inside the cavity through the hydrophobic effect ( $c f$. the crystal structure), we can see how the cage plays the role of bringing together a neutral substrate and an anion with which it can react through two orthogonal interactions, but this time resulting in a $\mathrm{C}-\mathrm{C}$ bond forming reaction.

This particular reaction is an old one $[45,46]$ and in itself not of the highest importance. The catalysis we observed is very slow in absolute terms; and looking at the reaction in more detail is made difficult by the poor solubility of bindone in water. The importance of these results, however, is that they open the possibility of using the cage to stabilise enolate anions and accumulate them around substrates attracted to the cage via the hydrophobic effect. Whether the reaction occurs inside the cavity or outside, this opens up the general possibility of using the cationic/hydrophobic surface of this cage and others like it as a general catalyst for aldol-type reactions, which would have substantial synthetic utility. We note that Mukherjee et al. have recently reported the condensation reactions of relatively acidic ketones with hydrophobic aldehydes using a trigonal prismatic $\left[\mathrm{Pd}^{2+}\right]_{6}$ coordination cage as a catalyst, which allows the reactions to proceed under much milder conditions than in the absence of a catalyst [58]. This can be attributed in part to the hydrophobicity of the cavity that increased the thermodynamic driving force for the elimination of water, and its expulsion into the bulk solvent, but the role of the positive charge of the cage in stabilising anionic intermediates has also been suggested [58], which is exactly in agreement with what we propose.

Supplementary Materials: The following are available online at http://www.mdpi.com/2624-8549/2/1/4/s1.

Author Contributions: Synthesis and catalysis measurements: C.M., C.G.P.T., and J.R.P.; data analysis, C.M.; crystallography, S.P.A. and C.G.P.T.; project supervision and manuscript preparation: M.D.W. All authors have read and agreed to the published version of the manuscript.

Funding: This research was funded by the EPSRC, grant number EP/K003224/1; and the European Union (H2020-MSCA-ITN grant 'NOAH', project ref. 765297). 
Acknowledgments: We thank the Diamond Light Source for the X-ray beamtime (proposal MT19876) and the staff of beamline I-19 for their assistance. Mr. Mark Cooper is thanked for his assistance with some of the early experimental measurements as part of an undergraduate project.

Conflicts of Interest: The authors declare no conflict of interest. The funders had no role in the design of the study; in the collection, analyses, or interpretation of data; in the writing of the manuscript, or in the decision to publish the results.

\section{References}

1. Brown, C.J.; Toste, F.D.; Bergman, R.G.; Raymond, K.N. Supramolecular catalysis in metal-ligand cluster hosts. Chem. Rev. 2015, 115, 3012-3025. [CrossRef]

2. Fang, Y.; Powell, J.A.; Li, E.; Wang, Q.; Perry, Z.; Kirchon, A.; Yang, X.; Xiao, Z.; Zhu, C.; Zhang, L.; et al. Catalytic reactions within the cavity of coordination cages. Chem. Soc. Rev. 2019, 48, 4707-4730. [CrossRef] [PubMed]

3. Yoshizawa, M.; Klosterman, J.K.; Fujita, M. Functional molecular flasks: New properties and reactions within discrete, self-assembled hosts. Angew. Chem. Int. Ed. 2009, 48, 3418-3438. [CrossRef] [PubMed]

4. Otte, M. Size-selective molecular flasks. ACS Catal. 2016, 6, 6491-6510. [CrossRef]

5. Zhang, D.; Ronson, T.K.; Nitschke, J.R. Functional capsules via subcomponent self-assembly. Acc. Chem. Res. 2018, 51, 2423-2436. [CrossRef] [PubMed]

6. Jing, X.; He, C.; Zhao, L.; Duan, C. Photochemical properties of host-guest supramolecular systems with structurally confined metal-organic capsules. Acc. Chem. Res. 2019, 52, 100-109. [CrossRef]

7. Hong, C.M.; Bergman, R.G.; Raymond, K.N.; Toste, F.D. Self-Assembled Tetrahedral Hosts as Supramolecular Catalysts. Acc. Chem. Res. 2018, 51, 2447-2455. [CrossRef]

8. Catti, L.; Zhang, Q.; Tiefenbacher, K. Advantages of catalysis in self-assembled molecular capsules. Chem. Eur. J. 2016, 22, 9060-9066. [CrossRef]

9. Gao, W.-X.; Zhang, H.-N.; Jin, G.-X. Supramolecular catalysis based on discrete heterometallic coordination-driven metallacycles and metallacages. Coord. Chem. Rev. 2019, 386, 69-84. [CrossRef]

10. Ward, M.D.; Hunter, C.A.; Williams, N.H. Coordination cages based on bis(pyrazolylpyridine) ligands: Structures, dynamic behavior, guest binding, and catalysis. Acc. Chem. Res. 2018, 51, 2073-2082. [CrossRef]

11. Yoshizawa, M.; Tamura, M.; Fujita, M. Diels-alder in aqueous molecular hosts: Unusual regioselectivity and efficient catalysis. Science 2006, 312, 251-254. [CrossRef] [PubMed]

12. Murase, T.; Horiuchi, S.; Fujita, M. Naphthalene Diels-Alder in a self-assembled molecular flask. J. Am. Chem. Soc. 2010, 132, 2866-2867. [CrossRef]

13. Kang, J.; Rebek, J., Jr. Acceleration of a Diels-Alder reaction by a self-assembled molecular capsule. Nature 1997, 385, 50-52. [CrossRef] [PubMed]

14. Kang, J.; Hilmersson, G.; Santamaría, J.; Rebek, J., Jr. Diels-Alder reactions through reversible encapsulation. J. Am. Chem. Soc. 1998, 120, 3650-3656. [CrossRef]

15. Kaphan, D.M.; Toste, F.D.; Bergman, R.G.; Raymond, K.N. Enabling new modes of reactivity via constrictive binding in a supramolecular-assembly-catalyzed aza-Prins cyclization. J. Am. Chem. Soc. 2015, 137, 9202-9205. [CrossRef] [PubMed]

16. Hart-Cooper, W.M.; Zhao, C.; Triano, R.M.; Yaghoubi, P.; Ozores, H.L.; Burford, K.N.; Toste, F.D.; Bergman, R.G.; Raymond, K.N. The effect of host structure on the selectivity and mechanism of supramolecular catalysis of Prins cyclizations. Chem. Sci. 2015, 6, 1383-1393. [CrossRef]

17. Hastings, C.J.; Bergman, R.G.; Raymond, K.N. Origins of large rate enhancements in the Nazarov cyclisation catalysed by supramolecular encapsulation. Chem. Eur. J. 2014, 20, 3966-3973. [CrossRef]

18. Hastings, C.J.; Pluth, M.D.; Bergman, R.G.; Raymond, K.N. Enzymelike catalysis of the Nazarov cyclization by supramolecular encapsulation. J. Am. Chem. Soc. 2010, 132, 6938-6940. [CrossRef]

19. Fiedler, D.; van Halbeek, H.; Bergman, R.G.; Raymond, K.N. Supramolecular catalysis of unimolecular rearrangements: Substrate scope and mechanistic insights. J. Am. Chem. Soc. 2006, 128, 10240-10252. [CrossRef]

20. Cullen, W.; Takezawa, H.; Fujita, M. Demethylenation of cyclopropanes via photoinduced guest-to-host electron transfer in an $\mathrm{M}_{6} \mathrm{~L}_{4}$ cage. Angew. Chem. Int. Ed. 2019, 58, 9171. [CrossRef] 
21. Dalton, D.M.; Ellis, S.R.; Nichols, E.M.; Mathies, R.A.; Toste, F.D.; Bergman, R.G.; Raymond, K.N. Supramolecular $\left[\mathrm{Ga}_{4} \mathrm{~L}_{6}\right]^{12-}$ cage photosensitizes 1,3-rearrangement of encapsulated guest via photoinduced electron transfer. J. Am. Chem. Soc. 2015, 137, 10128-10131. [CrossRef] [PubMed]

22. Murase, T.; Takezawa, H.; Fujita, M. Photo-driven anti-Markovnikoz alkyne hydration in self-assembled hollow complexes. Chem. Commun. 2011, 47, 10960-10962. [CrossRef] [PubMed]

23. Murase, T.; Nishijima, Y.; Fujita, M. Unusual photoreaction of triquinacene within self-assembled hosts. Chem. Asian J. 2012, 7, 826-829. [CrossRef] [PubMed]

24. Martí-Centelles, V.; Lawrence, A.L.; Lusby, P.J. High activity and efficient turnover by a simple, self-assembled “artificial Diels-Alderase". J. Am. Chem. Soc. 2018, 140, 2862-2868. [CrossRef] [PubMed]

25. Cai, L.-X.; Li, S.-C.; Yan, D.-N.; Zhou, L.-P.; Guo, F.; Sun, Q.-F. Water-soluble redox-active cage hosting polyoxometalates for selective desulfurization catalysis. J. Am. Chem. Soc. 2018, 140, 4869-4876. [CrossRef] [PubMed]

26. Bender, T.A.; Bergman, R.G.; Raymond, K.N.; Toste, F.D. A supramolecular strategy for selective catalytic hydrogenation independent of remote chain length. J. Am. Chem. Soc. 2019, 141, 11806-11810. [CrossRef]

27. Jongkind, L.J.; Caumes, X.; Hartendorp, A.P.T.; Reek, J.N.H. Ligand template strategies for catalyst encapsulation. Acc. Chem. Res. 2018, 51, 2115-2128. [CrossRef]

28. Tidmarsh, I.S.; Faust, T.B.; Adams, H.; Harding, L.P.; Russo, L.; Clegg, W.; Ward, M.D. Octanuclear cubic coordination cages. J. Am. Chem. Soc. 2008, 130, 15167-15175. [CrossRef]

29. Cullen, W.; Misuraca, M.C.; Hunter, C.A.; Williams, N.H.; Ward, M.D. Highly efficient catalysis of the Kemp elimination in the cavity of a cubic coordination cage. Nat. Chem. 2016, 8, 231-236. [CrossRef]

30. Cullen, W.; Metherell, A.J.; Wragg, A.B.; Taylor, C.G.P.; Williams, N.H.; Ward, M.D. Catalysis in a cationic coordination cage using a cavity-bound guest and surface-bound anions: Inhibition, activation, and autocatalysis. J. Am. Chem. Soc. 2018, 140, 2821-2828. [CrossRef]

31. Whitehead, M.; Turega, S.; Stephenson, A.; Hunter, C.A.; Ward, M.D. Quantification of solvent effects on molecular recognition in polyhedral coordination cage hosts. Chem. Sci. 2013, 4, 2744-2751. [CrossRef]

32. Turega, S.; Cullen, W.; Whitehead, M.; Hunter, C.A.; Ward, M.D. Mapping the internal recognition surface of an octanuclear coordination cage using guest libraries. J. Am. Chem. Soc. 2014, 136, 8475-8483. [CrossRef] [PubMed]

33. Metherell, A.J.; Cullen, W.; Williams, N.H.; Ward, M.D. Binding of hydrophobic guests in a coordination cage cavity is driven by liberation of 'high-energy' water. Chem. Eur. J. 2018, 24, 1554-1560. [CrossRef] [PubMed]

34. Yang, X.; Hahn, B.P.; Jones, R.A.; Wong, W.-K.; Stevenson, K.J. Synthesis of an octanuclear Eu(III) cage from $\mathrm{Eu}_{4}{ }^{2+}$ : Chloride anion encapsulation, luminescence, and reversible $\mathrm{MeOH}$ adsorption via a porous supramolecular architecture. Inorg. Chem. 2007, 46, 7050-7054. [CrossRef] [PubMed]

35. Bilyachenko, A.N.; Khrustalev, V.N.; Zubavichus, Y.V.; Vologzhanina, A.V.; Astakhov, G.S.; Gutsul, E.I.; Shubina, E.S.; Levitsky, M.M. High-nuclearity $\left(\mathrm{Cu}_{8}\right.$-based) cage silsesquioxanes: Synthesis and structural study. Cryst Growth Des. 2018, 18, 2452-2457. [CrossRef]

36. Elahi, S.M.; Rajasekharan, M.V. Spherical octanuclear clusters in a Na-Ln-dipic system: Encapsulation of a nitrate ion and incorporation of water nonamers and dodecamers. CrystEngComm 2015, 17, 7191-7198. [CrossRef]

37. Freudenreich, J.; Dalvit, C.; Süss-Fink, G.; Therrien, B. Encapsulation of photosensitizers in hexa- and octanuclear organometallic cages: Synthesis and characterization of carceplex and host-guest systems in solution. Organometallics 2013, 32, 3018-3033. [CrossRef]

38. Cullen, W.; Turega, S.; Hunter, C.A.; Ward, M.D. Virtual screening for high affinity guests for synthetic supramolecular receptors. Chem. Sci. 2015, 6, 2790-2794. [CrossRef]

39. Taylor, C.G.P.; Cullen, W.; Collier, O.M.; Ward, M.D. A quantitative study of the effects of guest flexibility on binding inside a coordination cage host. Chem. Eur. J. 2017, 23, 206-213. [CrossRef]

40. Pluth, M.D.; Bergman, R.G.; Raymond, K.N. Acid catalysis in basic solution: A supramolecular host promotes orthoformate hydrolysis. Science 2007, 316, 85-88. [CrossRef]

41. Pluth, M.D.; Bergman, R.G.; Raymond, K.N. The acid hydrolysis mechanism of acetals catalyzed by a supramolecular assembly in basic solution. J. Org. Chem. 2009, 74, 58-63. [CrossRef] [PubMed]

42. Pluth, M.D.; Bergman, R.G.; Raymond, K.N. Making amines strong bases: Thermodynamic stabilization of protonated guests in a highly-charged supramolecular host. J. Am. Chem. Soc. 2007, 129, 11459-11467. [CrossRef] 
43. Jacob, J.; Sigalov, M.; Becker, J.Y.; Ellern, A.; Khodorkovsky, V. Self-condensation of 1,3-indandione: A reinvestigation. Eur. J. Org. Chem. 2000, 2047-2055. [CrossRef]

44. Sigalov, M.; Krief, P.; Shapiro, L.; Khodorkovsky, V. Inter- and intramolecular C-H…O bonding in the anions of 1,3-indandione derivatives. Eur. J. Org. Chem. 2008, 673-683. [CrossRef]

45. Wislicenus, W. Ueber die vereinigung verschiedener ester durch natrium. Ber. Dtsch. Chem. Ges. 1887, $20,589$. [CrossRef]

46. Wislicenus, W. Einwirkung von essigester auf phtalsäureester. Annalen 1888, 246, 347-355.

47. Allan, D.R.; Nowell, H.; Barnett, S.A.; Warren, M.R.; Wilcox, A.; Christensen, J.; Saunders, L.K.; Peach, A.; Hooper, M.T.; Zaja, L.; et al. A novel dial air-bearing fixed- $\chi$ diffractometer for small-molecular single-crystal X-ray diffraction on beamline I-19 at Diamond Light Source. Crystals 2017, 7, 336. [CrossRef]

48. Taylor, C.G.P.; Argent, S.P.; Ludden, M.D.; Piper, J.R.; Mozaceanu, C.; Barnett, S.A.; Ward, M.D. One guest or two? A crystallographic and solution study of guest binding in a cubic coordination cage. Chem. Eur. J. 2019, in press. [CrossRef]

49. Turega, S.; Whitehead, M.; Hall, B.R.; Meijer, A.J.H.M.; Hunter, C.A.; Ward, M.D. Shape-, size- and functional group-selective binding of small organic guests in a paramagnetic coordination cage. Inorg. Chem. 2013, 52, 1122-1132. [CrossRef]

50. Mecozzi, S.; Rebek, J. The 55\% solution: A formula for molecular recognition in the liquid state. Chem. Eur. J. 1998, 4, 1016-1022. [CrossRef]

51. Rebek, J. Molecular behaviour in small spaces. Acc. Chem. Res. 2009, 42, 1660-1668. [CrossRef] [PubMed]

52. Puttreddy, R.; Beyeh, N.K.; Kalenius, E.; Ras, R.H.A.; Rissanen, K. 2-Methylresorcinarene: A very high packing coefficient in a mono-anion based dimeric capsule and the X-ray crystal structure of the tetra-anion. Chem. Commun. 2016, 52, 8115-8118. [CrossRef] [PubMed]

53. Zhang, W.; Yang, D.; Zhao, J.; Hou, L.; Sessler, J.L.; Yang, X.-J.; Wu, B. Controlling the recognition and reactivity of alkyl ammonium guests using an anion coordination-based tetrahedral cage. J. Am. Chem. Soc. 2018, 140, 5248-5256. [CrossRef] [PubMed]

54. Djemili, R.; Kocher, L.; Durot, S.; Peuronen, A.; Rissanen, K.; Heitz, V. Positive allosteric control of guests encapsulation by metal binding to covalent porphyrin cages. Chem. Eur. J. 2019, 25, 1481-1487. [CrossRef] [PubMed]

55. Metherell, A.J.; Ward, M.D. Geometric isomerism in coordination cages based on tris-chelate vertices: A tool to control both assembly and host/guest chemistry. Dalton Trans. 2016, 45, 16096-16111. [CrossRef]

56. Spek, A.L. PLATON SQUEEZE: A tool for the calculation of disordered solvent contribution to the calculated structure factors. Acta Crystallogr. C. Sruct. Chem. 2015, 71, 9-18. [CrossRef]

57. Taylor, C.G.P.; Metherell, A.J.; Argent, S.P.; Ashour, F.M.; Williams, N.H.; Ward, M.D. Coordination cage catalysed hydrolysis of organophosphates: Cavity or surface based? Chem. Eur. J. 2019, in press. [CrossRef]

58. Das, P.; Kumar, A.; Howlader, P.; Mukherjee, P.S. A self-assembled trigonal prismatic molecular vessel for catalytic dehydration reactions in water. Chem. Eur. J. 2017, 23, 12565-12574. [CrossRef]

(C) 2020 by the authors. Licensee MDPI, Basel, Switzerland. This article is an open access article distributed under the terms and conditions of the Creative Commons Attribution (CC BY) license (http://creativecommons.org/licenses/by/4.0/). 